\title{
Wideband to concurrent tri-band frequency reconfigurable microstrip patch antenna for wireless communication
}

\author{
SONIA SHARMA AND CHANDRA CHARU TRIPATHI
}

\begin{abstract}
This paper proposes a novel wideband to concurrent tri-band frequency reconfigurable microstrip antenna. The frequency reconfiguration is achieved by using a pair of PIN diodes in the antenna feed line to switch the antenna either in wideband mode or in concurrent tri-band mode. In order to improve the bandwidth and gain of the antenna for wideband operation, the properties of J-K inverter and split ring resonators are exploited. To demonstrate the versatility of this concept a prototype is fabricated and tested here. The tested results in wideband mode shows that the proposed antenna operates from 3.58 to $-3.82 \mathrm{GHz}$, which is 4.08 times larger than the bandwidth of a simple microstrip patch antenna. In the concurrent tri-band mode frequency tuning is done by microstrip open stub at $1.5 \mathrm{GHz}, 1.9 \mathrm{GHz}$, and $3.5 \mathrm{GHz}$. Gain of the proposed antenna is better than $2.7 \mathrm{~dB}$ in wideband mode and $2.7 \mathrm{~dB}$ in concurrent tri-band mode.
\end{abstract}

Keywords: Wideband, Frequency reconfigurable antenna, JK inverter, CSRR

Received 17 December 2015; Revised 6 June 2016; Accepted 9 June 2016; first published online 1 August 2016

\section{INTRODUCTION}

The next generation wireless systems require wideband as well as multiband operation capabilities in a single device to enable more data transfer capacity in addition to multi-band multistandard operating capabilities. Thus, such wireless systems provide the advantage of high speed along with the low out-of-band radiation when operated for multi band applications. The wireless applications like global system for mobile (GSM) and CDMA requires narrow bandwidth while BWA, wireless local area network (WLAN), and worldwide interoperability for microwave access (WiMax) requires broad bandwidth for their operation. So, depending on the user's bandwidth requirement for specific application, antenna must reconfigure its bandwidth around resonating frequency.

So far researchers have mainly focused either on very wideband antenna [1-2] or multi-band antenna [3]. Also, a number of techniques have also been reported to achieve wideband and narrowband operation simultaneously in a single antenna structure [4-7]. A reconfigurable wideband to multiband antenna using two patch elements containing two C-Slots is proposed in literature [4]. A Vivaldi antenna loaded with $15 \mathrm{P}$ type -Insulator- $\mathrm{N}$ type (PIN) diodes in between the two ring slots is reported in [5] to provide switching between a wideband and six discrete narrowband frequency spectrums. Further, a dual port microstrip circular

Department of Electronics and Communication Engineering, University Institute of Engineering and Technology, Kurukshetra University, Kurukshetra-136119, India Corresponding author:

S. Sharma

Email: sonia99o@gmail.com antenna integrated with reconfigurable band pass filter in the feed line have been reported in [6] for switching either in wide band state $(3.8-6 \mathrm{GHz})$ or narrow band state (3.9$4.82 \mathrm{GHz}$ ). In [7], a unique combination of wide and narrow band antenna by utilizing the space between two tapered slots is utilized to integrate a narrow band antenna is presented. In all these reported works [4-7], integrated wideband and multiband antenna is obtained by number of techniques viz. altering the shape of radiating element or shorting the antenna and or by combining two different antennas together. In all these techniques, shape of the radiating element is modified hence radiation characteristics of the antenna is affected. In most of the design, dual port feeding mechanism is used, which introduces undesired mutual coupling effects between ports, and therefore extra labor is required for port isolation, resulting in increased complexity of the design. This may compromise the goal of combining the wideband and multiband antennas together.

In this paper, a novel wideband to concurrent tri-band antenna is proposed. The beauty of the proposed antenna is that it has features of two reconfigurable states: one concurrent tri-band at $1.5 \mathrm{GHz}(\mathrm{GSM}), 1.9 \mathrm{GHz}$ (3G, $4 \mathrm{G}, \mathrm{GSM})$, $3.5 \mathrm{GHz}$ (WLAN) and one wideband (3.58-3.82 GHz) (Wi-Max) using same radiating element. This overcomes the requirement for increasing the surface area for designing wideband and multiband antennas together. In contrast to the earlier works, successful efforts have been done to improve the antenna parameter in wide band mode. Only two switching elements are used in the feed line to reconfigure the antenna from wideband to multiband; hence it is unique design as it does not alter the radiating element itself. Further, it does not require port isolation because single 
radio frequency $(\mathrm{RF})$ feed is split in two parts by a pair of PIN diodes and the position of PIN diodes are selected such that they provide good matching and isolation in both operating modes. In the design, microstrip baluns are used to isolate the DC source from RF signal. From hardware perspective, the proposed antenna offers lower circuit complexity and ease of reconfiguration. The proposed design can be used for cognitive radio system so that antenna can smartly reconfigure its operating state according to bandwidth requirement of user.

\section{DESIGN STRATEGY}

The geometry of the proposed wideband to tri-band concurrent reconfigurable antenna is shown in Fig. 1(a) and (b). The proposed antenna is designed on $1.57 \mathrm{~mm}$ thick substrate having relative dielectric constant $\varepsilon_{r}=4.4$. The complete design strategy is divided into three parts: design and optimization of broadband impedance matching network, design of open microstrip stub for tri-band mode, and selection of PIN diode position. In first part a reactive matching network is added in the feed line to compensate the hasty frequency variation on the input impedance of microstrip antenna [8]. Further, a pair of split ring resonators (SRR) is added to improve the wideband characteristics [9]. In second part, by applying parametric analysis on the open stub length; frequencies in the narrow-band can be independently controlled without affecting the wideband operations. In third part, position of PIN diode is selected such that it offers good matching as well as isolation in both operating modes. The details of the forgoing are as follows:

\section{A) Broad band impedance matching network}

\section{1) J-K INVERTER DESIGN}

In this section, the design equations for the calculation of J-K inverter parameters are presented. The design starts with the calculation of input impedance of a patch antenna, which is used to design a broadband matching network subsequently.

The input impedance of microstrip patch antenna is modeled by parallel resonant equivalent circuit [1] as shown in Fig. 2(a) and given by equation (1)

$$
Z_{\text {in }}=\frac{R_{10}}{1+j Q \dot{v}},
$$

where $Q=\pi R_{10} / 2 Z_{c 1}$ is the quality factor of patch antenna, $R_{10}$ is the real part and $Z_{c 1}$ is the imaginary part of antenna's input impedance and term $\dot{v}$ is given by equation (2)

$$
\dot{v}=\frac{\omega}{\omega_{r}}-\frac{\omega_{r}}{\omega} \text {. }
$$

The equivalent model parameters of simple microstrip patch antenna excited in $T M_{10}$ mode are given in equations $(3-5)$

$$
\begin{gathered}
C_{10}=\frac{\varepsilon_{0} \varepsilon_{r} L W}{2 h} \cos ^{-2} \frac{\pi x_{0}}{L}, \\
R_{10}=\frac{\omega \mu_{0} h}{k_{0}^{2} \varepsilon_{r} \delta_{e f f}} \frac{2}{L W} \cos ^{2} \frac{\pi x_{0}}{L}, \\
L_{10}=\frac{1}{C_{10} \omega_{r}^{2}},
\end{gathered}
$$

where $\omega=$ frequency variable, $\omega_{r}=$ resonant frequency, $\varepsilon_{0}=$ permittivity of free space, $\mu_{\mathrm{o}}=$ permeability of free space, $\varepsilon_{r}=$ permittivity of substrate, $x_{\mathrm{o}}=$ probe position, $k_{\mathrm{o}}=$ propagation constant, $h=$ height of substrate, $\delta_{e f f}=$ skin depth, $L=$ length, $W=$ width of antenna.

The main reason of inherent low bandwidth in microstrip antenna is the resonant behavior of input impedance as given

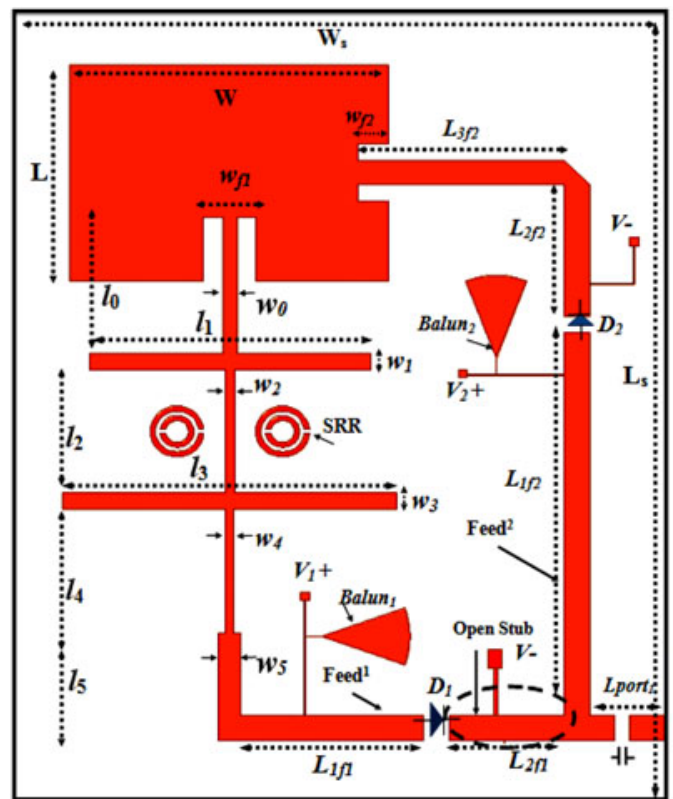

(a)

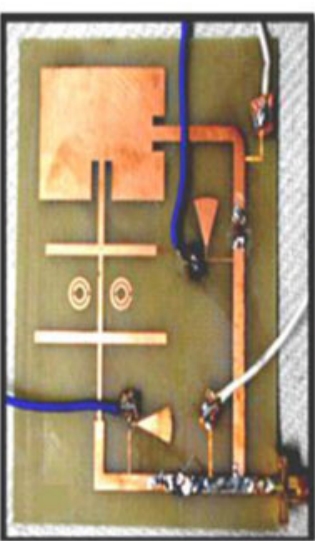

(b)

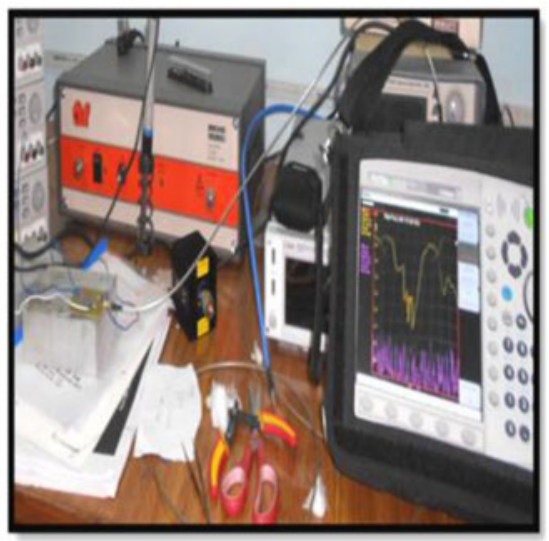

(c)

Fig. 1. (a) Proposed layout of antenna, (b) fabricated photograph, (c) experimental setup. 


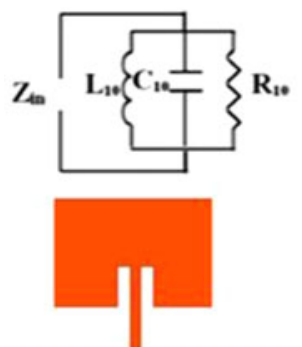

(a)

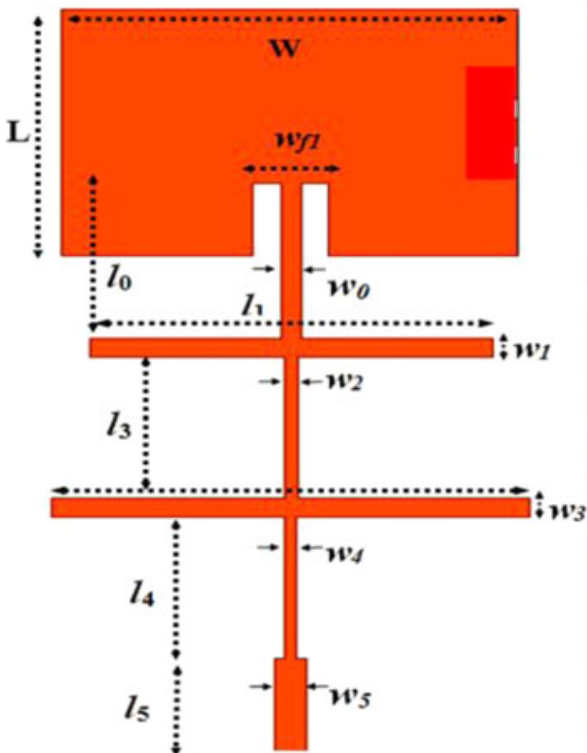

(b)

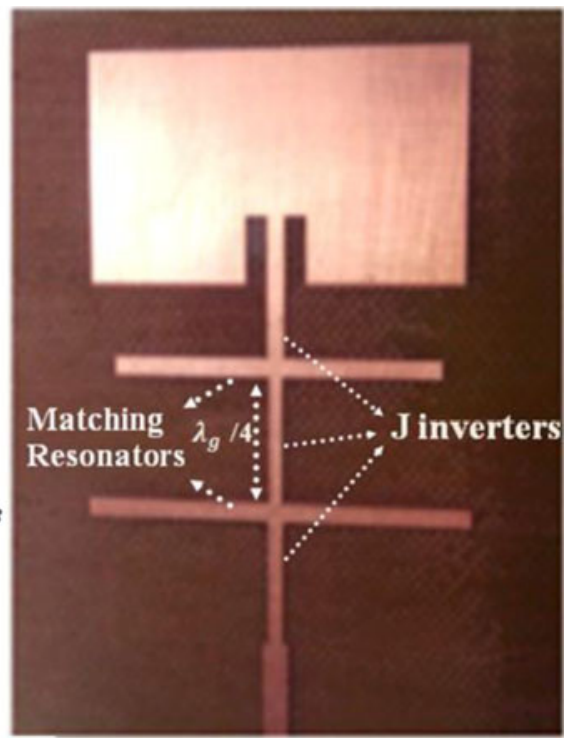

(c)

Fig. 2. (a) Equivalent circuit model of patch antenna, (b) schematic layout of patch antenna loaded with transmission line equivalent J-K inverter, (c) fabricated photograph.

in equation (1). So to reimburse the frequency variation on the input impedance; a reacting matching network should be designed, which matches the antenna impedance over a bigger bandwidth.

An admittance J-K inverter [8], which is an ideal quarter wave transmission line section of characteristic admittance $J$ is added in between antenna and port. Figure 3 shows the traditional schematic of $n$-stage broadband matching network, which consists of $n$ matching resonators and $n+1 J$ inverters. First resonator $i=1$ belongs to antenna itself, whereas $i=2,3$, 4 belongs to matching network with $Y_{c i}$ characteristic admittance. $J_{n, n+1}$ is the final impedance scaling admittance inverter and $J_{i, i+1}$ is the admittance inverter between $i$ and $i+1$ resonator. Let the order of matching network $n$ be 3 and high impendence value for $Z_{c}^{23}$ be $130 \Omega$. For simplicity impedance of transmission line resonator are chosen to be equal $Y_{c 2}=Y_{c 3}$ and $Y_{c 2}$ is computed by equation (6)

$$
J_{i, i+1}=\Delta \sqrt{\frac{Y_{c i} Y_{c i, i+1}}{g_{i} g_{i+1}}},
$$

where $\Delta=\tan (\pi / 2 B), B$ is fractional bandwidth of antenna, parameters $g_{i}$ are the elements of butter worth low pass prototype filter with value $g_{\mathrm{o}}=g_{4}=1, g_{1}=g_{3}=1 / \delta$, where $\delta$ decrement factor and calculated using $\delta=\pi / 2 \Delta Q$. Parameter $J_{i, i+1}$ is computed using formula given in equation ( 7 ) and other different network parameter should satisfy the following equations $(7-10)$

$$
\begin{gathered}
Y_{c i, i+1}=J_{i, i+1} \cos \left(\frac{\pi}{4} B\right), \\
J_{12}=\sqrt{\frac{\Delta Y_{c 2}}{R_{\circ} g_{2}}}, \\
J_{n, n+1}=\sqrt{\frac{\Delta Y_{c n}}{Z_{0} g_{n} g_{n+1}}}, \\
Y_{c 2}=\frac{g_{2}}{\Delta R_{0}} .
\end{gathered}
$$

After calculating the admittance for matching resonator; translation of reactive matching network into practical transmission line network is done as shown in Fig. 2(b) and (c). The calculated value of dimension for the proposed antenna are $R_{\mathrm{o}}=49.25 \Omega, Z_{c 1}=0.4888 \Omega, \delta=0.0625, Y_{c 2}=70.55$, $Z_{c 23}=130 \Omega, L=26.2 \mathrm{~mm}, W=36.24 \mathrm{~mm}, L_{s}=95 \mathrm{~mm}$, $W_{s}=75 \mathrm{~mm}, l_{\mathrm{o}}=16.5 \mathrm{~mm}, l_{1}=30.4 \mathrm{~mm}, l_{2}=15 \mathrm{~mm}, l_{3}=$ $37.14 \mathrm{~mm}, l_{4}=15 \mathrm{~mm}, l_{5}=13 \mathrm{~mm}, w_{0}=1.588 \mathrm{~mm}, w_{1}=$ $2 \mathrm{~mm}, w_{2}=1.06 \mathrm{~mm}, w_{3}=2 \mathrm{~mm}, w_{4}=0.857 \mathrm{~mm}, w_{5}=$ $2.44 \mathrm{~mm}$.

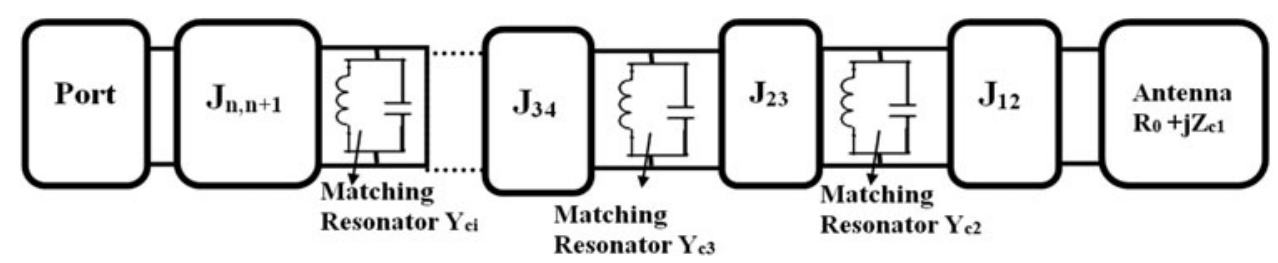

Fig. 3. Schematic of $n$-stage J-K inverter. 


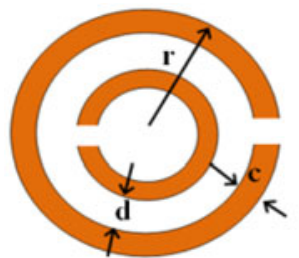

(a)

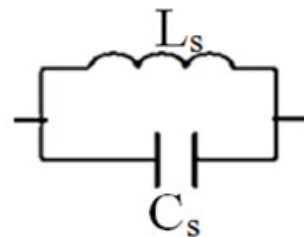

(b)
Fig. 4. Layout of (a) SRR, (b) equivalent circuit model for SRR.

\section{2) SRR DESIGN}

To improve the impedance bandwidth and operating parameter of proposed antenna; a pair of SRR is integrated in between the microstrip equivalent of $\mathrm{J}-\mathrm{K}$ inverter structure. A succinct theory and design equations for equivalent model for SRR are described in this part. SRR can improve some prescribed antenna features i.e. impedance matching, gain, efficiency, directivity, front-to-back ratio etc. [9-10]. Along these features SRR are used to improve the broad banding; and suppressing the sideband and mutual coupling between two radiators [10-11].

The structure of SRR and its equivalent-circuit model are depicted in Fig. 4(a) and (b). The SRR is modeled as a shunt LC resonator tank [12-13]. The capacitance $C_{s}$ is calculated by the capacitance of a long cylindrical capacitor and given by equation (11).

$$
C_{s}=\frac{2 \pi h \varepsilon}{\ln (r /(r-d))},
$$

where $h$ is the height of substrate, $d$ is the distance between the two SRR rings, $r$ is the radius, and $\varepsilon$ is permittivity of material.

Inductance $L_{s}$ is calculated by equation (12).

$$
L_{s}=2 \pi r L_{p}
$$

where $L_{p}$ is inductance per unit length.

The resonance frequency of SRR is given by equation (13)

$$
f_{\mathrm{o}}^{S R R}=\frac{1}{2 \pi \sqrt{C_{s}+C_{\mathrm{o}}}}
$$

where $C_{o}=2 \pi r C p$ is the fringing capacitance and $C_{p}$ is the capacitance per unit length of two parallel coplanar strips. The SRR itself has little radiation since the radiation from the outer ring would cancel itself by inner ring slot. The selections of dimension, position, gap between SRR are based on parametric study. The radius of outer ring of SRR is $r=$ $3.02 \mathrm{~mm}$, width of SRR ring is $c=0.6 \mathrm{~mm}$ and gap between two rings is $d=0.6 \mathrm{~mm}$.

\section{B) Open stub design}

Narrow band mode of the proposed antenna is selected by activating diode $D_{2}$ by applying $+5 \mathrm{~V}$ on DC pad $V_{2}$. In doing so the feed ${ }^{2}$ connected with open stub of length $L_{2 f_{1}}$ is selected for operation. Position of diode $D_{2}$ is selected such that when $D_{2}$ is ON then feed length $L_{1 f_{2}}$ in conjunction with $L_{2 f_{1}}$ gives good matching for the tri-band mode. So the frequency of operation can be independently controlled by the

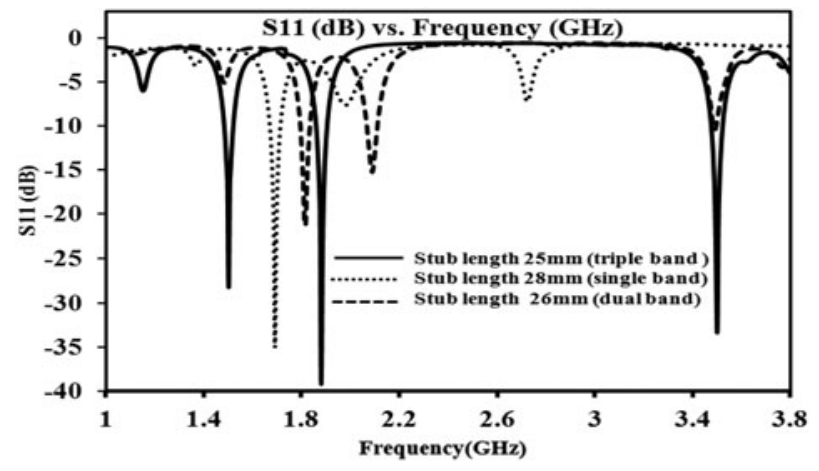

Fig. 5. Effect of change in length of open stub on $S_{11}$ parameter.

open stub length without affecting the wideband response. Figure 5 shows the effect of change in length of open stub (or position of diode $D_{1}$ ) on $S$ parameter. The results show that if stub length is $25 \mathrm{~mm}$ then a tri-band $(1.5,1.9$, and $3.5 \mathrm{GHz}$ ) response is obtained, if stub length is $26 \mathrm{~mm}$ then a dual band $(1.81,2 \mathrm{GHz})$ response is obtained and if stub length is $28 \mathrm{~mm}$ then a single band at $1.7 \mathrm{GHz}$ is obtained. For the proposed design the chosen stub length is $25 \mathrm{~mm}$ for concurrent tri-band operation.

\section{C) Positioning of PIN diode}

The position of PIN diode is selected after analyzing that there should be good matching in their respective operating mode. Position of diode $D_{1}$ is selected such that when $D_{1}$ is ON then feed length $L_{2 f_{1}}$ (part of feed ${ }^{1}$ ) in conjunction with $L_{1 f_{2}}$ (part of feed $^{2}$ acts as a open stub) gives good matching for the wideband. Similarly Diode $D_{2}$ is positioned such that feed length $L_{1 f_{2}}$ in addition with $L_{2 f_{1}}$ (part of feed ${ }^{1}$ acts as a open stub) gives good matching in tri-band mode. Figure 6 shows the portion of feed line to explain the isolation between feed lines in both operating modes. For wideband mode, in Fig. 6 diode $D_{1}$ is ON and diode $D_{2}$ is in OFF state so $D_{1}$ is replaced by its $\mathrm{ON}$ state equivalent circuit $\left(R_{s}=2.1 \Omega\right)$ and $D_{2}$ is replaced by OFF state equivalent circuit $\left(R_{p}=\mathrm{k} \Omega, C_{p}=\right.$ $0.17 \mathrm{pF})$. In this mode signal propagates through feed ${ }^{1}$ so there is propagation of signal from port ${ }^{1}$ to port $^{2}$ and no power should transfer from port ${ }^{1}$ to port $^{3}$ at 1.5, 1.9, 3.5 GHz (concurrent tri-band frequencies).

Simulated $S$ parameter results using equivalent circuit are shown in Fig. $7(\mathrm{a})$. Results clearly show $S_{21}$ is $-1.37 \mathrm{~dB}$ and $S_{31}$ is better than $25 \mathrm{~dB}$ at $1.5,1.9,3.5 \mathrm{GHz}$, which shows isolation of port $^{3}$ when operated in wideband mode. Similarly for concurrent tri-band mode, diode $D_{2}$ is replaced by its ON state

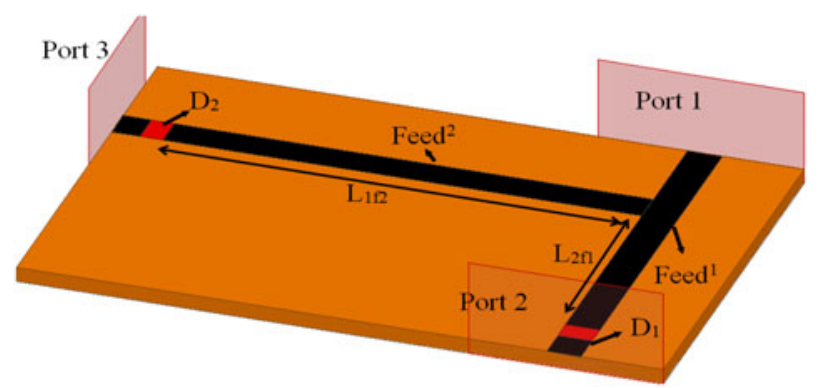

Fig. 6. Placement of PIN diodes in the feed line section. 


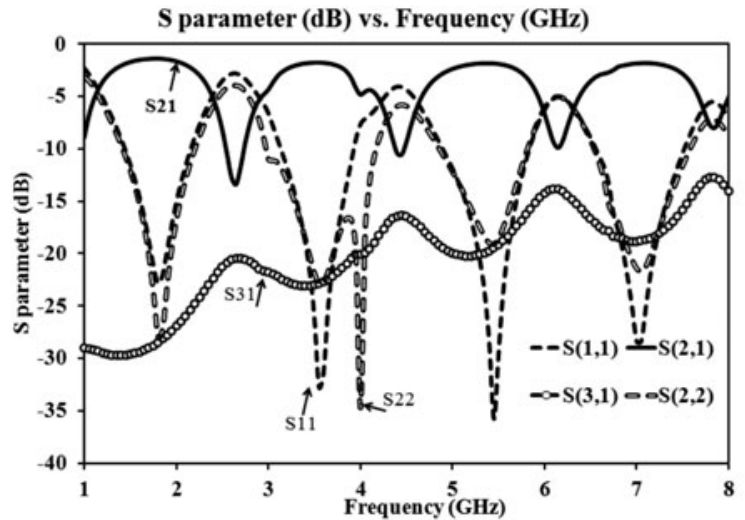

(a)

Fig. 7. $S$ parameter versus frequency in (a) wideband mode, (b) tri-band mode.

equivalent circuit and diode $D_{1}$ is replaced by OFF state equivalent circuit. In this mode signal propagates through feed $^{2}$ line so there is propagation of signal from port ${ }^{1}$ to port $^{3}$ and no power should transfer from port ${ }^{1}$ to port ${ }^{2}$ at wideband operating bandwidth. Simulated $S$ parameter shown in Fig. 7 (b) shows that $S_{21}$ is better than $25 \mathrm{~dB}$ from 3.58 to $3.825 \mathrm{GHz}$, which proves that there is no transmission of RF power towards port ${ }^{2}$. So there is no need of extra port isolation circuit because position of both diodes offer good matching and isolation in both operating modes.

\section{ANTENNA GEOMETRY AND FABRICATION}

The geometry and photograph of the proposed concurrent tri-band to wideband reconfigurable is shown in Fig. 1(a) and (b). The basic concept is based on sharing of one antenna structure between two different feed line sections. The feeding structure of antenna is toggle between feed ${ }^{1}$ and feed $^{2}$ by two PIN diodes $\left(D_{1}, D_{2}\right)$. Feed ${ }^{1}$ consists of a broadband J-K matching network and a pair of SRR. Feed ${ }^{2}$ consists of microstrip line and a microstrip open stub of length $L_{2 f_{1}}$. Remaining dimensional parameters for the proposed antenna are $w_{f_{1}}=4.412 \mathrm{~mm}, w_{f_{2}}=3.4 \mathrm{~mm}, L_{1 f_{1}}=$ $20.7 \mathrm{~mm}, L_{2 f_{1}}=13 \mathrm{~mm}, L_{1 f_{2}}=46.5 \mathrm{~mm}, L_{2 f_{2}}=15.9 \mathrm{~mm}$, $L_{3 f_{2}}=23.4 \mathrm{~mm}, \quad L_{\text {port }}=9 \mathrm{~mm} \quad w_{f_{1}}=4.412 \mathrm{~mm}, w_{f_{2}}=$ $3.4 \mathrm{~mm}, L_{1 f_{1}}=20.7 \mathrm{~mm}, L_{2 f_{1}}=13 \mathrm{~mm}, L_{1 f_{2}}=46.5 \mathrm{~mm}$, $L_{2 f_{2}}=15.9 \mathrm{~mm}, L_{3 f_{2}}=23.4 \mathrm{~mm}, L_{\text {port }}=9 \mathrm{~mm}$. Instead of using a lumped inductor a balun with $\theta=60^{\circ}$ is designed to provide a high isolation of RF signal towards DC. One $30 \mathrm{pF} R F$ capacitor is placed across the $0.2 \mathrm{~mm}$ wide gap in feed line section $L_{\text {port }}$ to maintain RF continuity and DC isolation. Infineon BAR 64-02 diodes (Size: $1.5 \times 0.7 \mathrm{~mm}^{2}$ ) are used to electrically connect/disconnect the microstrip feed line. Fabrication of the prototype is done using micro instrumentation and telemetry systems (MITS) printed circuit board (PCB) Prototyping Machine.

\section{RESULTS AND DISCUSSION}

Two PIN diodes $\left(D_{1}, D_{2}\right)$ are placed in the feed line of proposed antenna to toggle the antenna either in wideband mode or concurrent tri-band mode. In high frequency

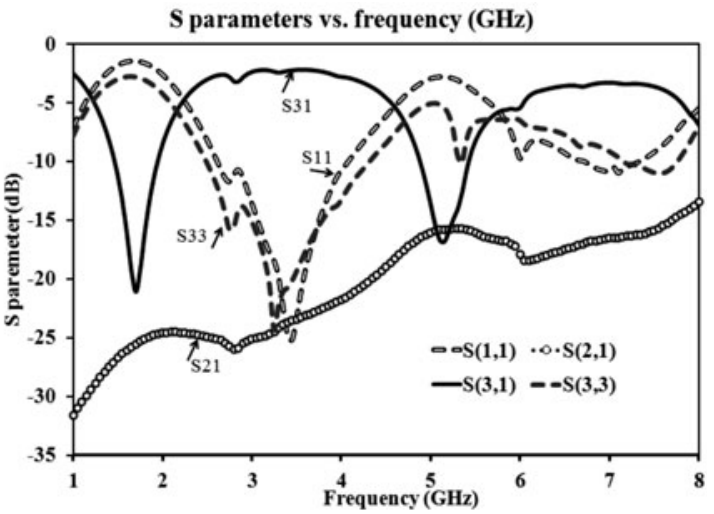

(b)

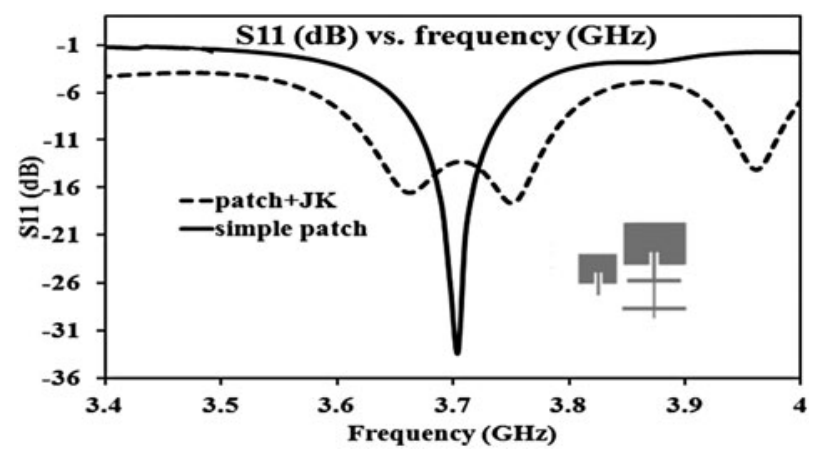

Fig. 8. $S_{11}(\mathrm{~dB})$ versus frequency showing the effect of adding J-K inverter.

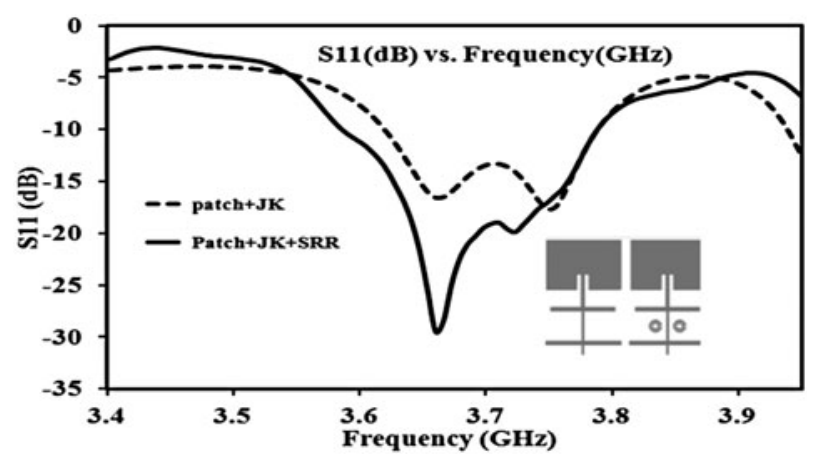

Fig. 9. $S_{11}(\mathrm{~dB})$ versus frequency showing the effect of adding SRR.

simulator software (HFSS) simulation, a strip of size $0.7 \times$ $3 \mathrm{~mm}^{2}$ is used to represent the PIN diode. Effect of actual PIN diode is incorporated by assigning strip by its equivalent circuit using lumped boundary condition. In forward bias, PIN diode is modeled with a forward resistance of $2.1 \Omega$ and in reverse bias it is modeled by a reverse parallel resistance $=3 \mathrm{~K} \Omega$ and a capacitance $=0.17 \mathrm{pF}$.

\section{A) Wideband mode}

In this part results are discussed to study the effect of adding $\mathrm{J}-\mathrm{K}$ inverter followed by effect of adding SRR in the simple microstrip antenna for wideband mode. Further, to validate the proposed work simulated results are verified with 
Table 1. Observed parameter in wideband mode.

\begin{tabular}{lllll}
\hline & & Simulated & Measured \\
\hline Case & Simple patch & J-K inverter & J-K + SRR & J-K + SRR \\
Frequency & $3.66-3.72 \mathrm{GHz}$ & $3.6-3.79 \mathrm{GHz}$ & $3.58-3.79 \mathrm{GHz}$ & $3.58-3.825 \mathrm{GHz}$ \\
Bandwidth & $60 \mathrm{MHz}$ & $190 \mathrm{MHz}$ & $210 \mathrm{MHz}$ & $245 \mathrm{MHz}$ \\
\hline
\end{tabular}

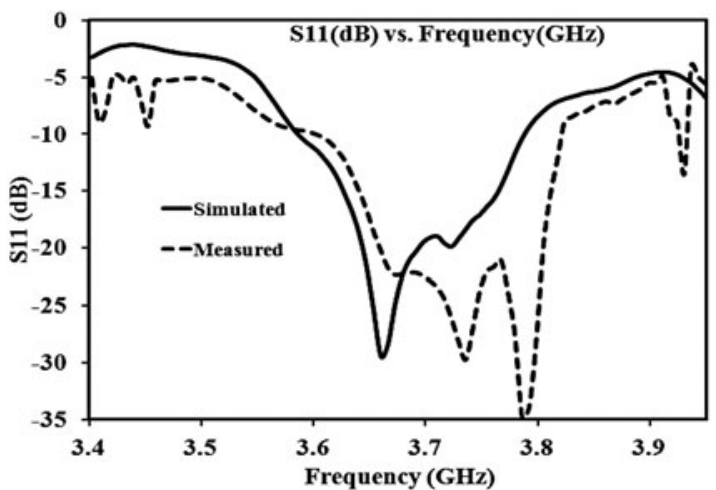

(a)

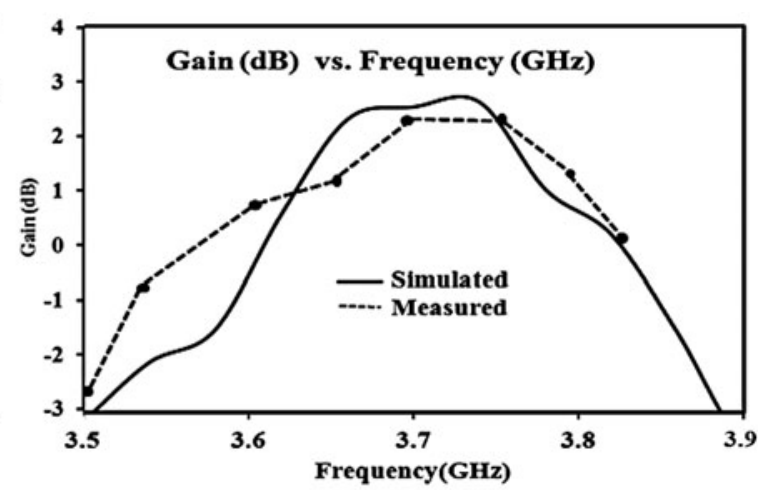

(b)

Fig. 10. Measured (a) $S_{11}(\mathrm{~dB})$ versus frequency, (b) gain (dB) versus frequency in wideband mode.

measured results. In simulation diode $D_{1}$ is considered as ON state when it is replaced by its $\mathrm{ON}$ state equivalent circuit. Practically PIN diode $D_{1}$ is activated by applying $+5 \mathrm{~V}$ on DC pad $V_{1}$ and ground signal on $V_{-}$pad.

Simulation results shown in Fig. 8 proves that by embedding $\mathrm{J}-\mathrm{K}$ inverter in a simple inset cut feed antenna; antenna matches at wider bandwidth. It is investigated that bandwidth of a simple patch antenna is $60 \mathrm{MHz}(3.66-3.72 \mathrm{GHz})$ whereas by incorporating broadband matching network bandwidth is increased to $190 \mathrm{MHz}(3.6-3.79 \mathrm{GHz})$, which is 3.16 times greater than a simple patch antenna.

Further, to improve the antenna characteristics in wideband mode; two SRR are added in between the feed line. From Fig. 9 it can be clearly concluded that antenna reflection coefficient are remarkably improved from $-20-30 \mathrm{~dB}$ and bandwidth is increased from $190 \mathrm{MHz}(3.6-3.79 \mathrm{GHz})$ to $210 \mathrm{MHz}(3.58-3.79 \mathrm{GHz})$. Hence operating parameter of the proposed design are successfully improved by including a pair of SRR in the feed line of antenna.

Now, simulated results for the proposed antenna are compared with the measured results in wideband mode as shown in Fig. 10(a) and (b) and tabulated in Table 1. Results shown in Fig. 10(a) reveals that simulated bandwidth is $210 \mathrm{MHz}$ $(3.58-3.79 \mathrm{GHz})$ whereas measured bandwidth is $245 \mathrm{MHz}$ $(3.58-3.825 \mathrm{GHz})$, which is 4.08 times larger than the bandwidth of a simple patch. The maximum value of measured

Table 2. Observed parameter in triple-band mode.

\begin{tabular}{|c|c|c|c|c|c|}
\hline \multicolumn{3}{|c|}{ Simulated parameter } & \multicolumn{3}{|c|}{ Measured parameter } \\
\hline Freq.(GHz) & $\begin{array}{l}\text { RL } \\
(\mathrm{dB})\end{array}$ & $\begin{array}{l}\text { Gain } \\
(\mathrm{dB})\end{array}$ & $\begin{array}{l}\text { Freq. } \\
\text { (GHz) }\end{array}$ & $\begin{array}{l}\text { RL } \\
(\mathrm{dB})\end{array}$ & $\begin{array}{l}\text { Gain } \\
\text { (dB) }\end{array}$ \\
\hline 1.5 & -28 & 3.5 & 1.56 & -27 & 2.8 \\
\hline 1.9 & -39 & 1.2 & 1.945 & -41 & 1 \\
\hline 3.5 & -33 & 1.25 & 3.513 & -44 & 0.8 \\
\hline
\end{tabular}

gain in wideband mode is $2.7 \mathrm{~dB}$ against the simulated value of $3 \mathrm{~dB}$ as shown in Fig. 10(b).

\section{B) Concurrent tri-band mode}

When diode $D_{2}$ is forward biased by applying $+5 \mathrm{~V}$ on DC pad $V_{2}$, the feed ${ }^{2}$ is selected for concurrent tri-band mode. Simulated and measured results are compared in Fig. 11 and tabulated in Table 2. Simulated tri-band response observed at $1.5,1.9$ and $3.5 \mathrm{GHz}$ while measured response are at $1.565,1.945,3.513 \mathrm{GHz}$. The results show that the simulated and measured $S_{11}$ parameter is better than $-25 \mathrm{~dB}$ in all the bands. The measured results are satisfactory; however frequency shift with respect to simulated results is attributed to the OFF state capacitance of PIN diodes, which produce loading effect [14] on the antenna that shifts the resonance frequency. Simulated gain is compared by measured gain as shown in Fig. 11(b). Simulated peak gain at first band $(1.5 \mathrm{GHz})$ is greater than $3.5 \mathrm{~dB}$ while measured peak gain is about $2.8 \mathrm{~dB}$. In the second band $(1.9 \mathrm{GHz})$ simulated value of gain is $1.2 \mathrm{~dB}$ whereas measured value of gain is $1 \mathrm{~dB}$. In third band at $3.5 \mathrm{GHz}$ simulated value of gain is $1.25 \mathrm{~dB}$ whereas measured value is $0.8 \mathrm{~dB}$.

Figure 12 shows the electric field distribution to explain the electromagnetic coupling for wideband mode and tri-band mode. Figure 12(a) shows the electric field distribution in concurrent tri-band mode. The maximum intensity of electric field is distributed under feed ${ }^{2}$ line, which clearly shows that maximum power flows through feed ${ }^{2}$ line. The value of electric field under feed ${ }^{2}$ (red color) is nearly 50 times greater as compared with feed ${ }^{1}$ (yellow color) and therefore there is low coupling of power through feed ${ }^{2}$ to feed $^{1}$ in tri-band mode. Figure 12(b) shows the field distribution for wideband mode. It clearly shows that electric field is highly intense 


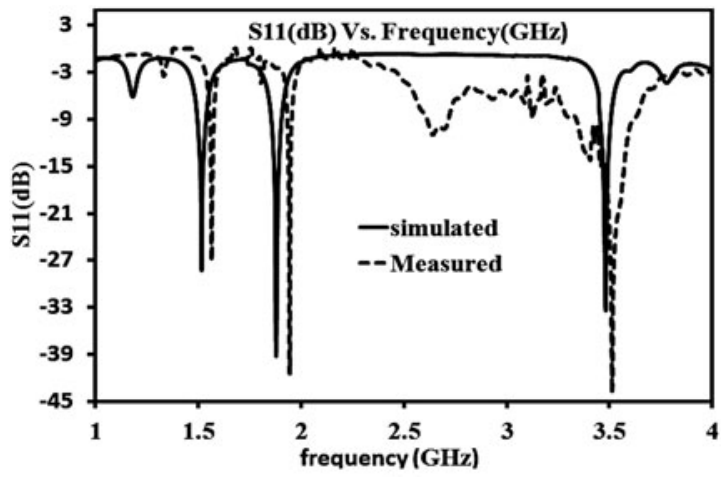

(a)

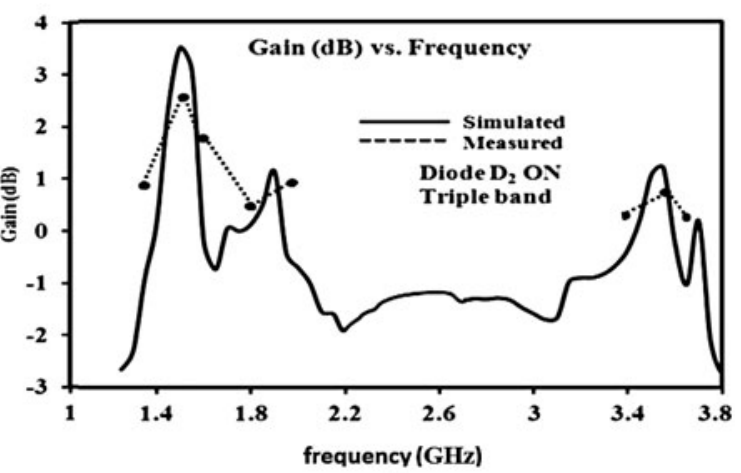

(b)

Fig. 11. (a) $S_{11}(\mathrm{~dB})$ versus frequency, (b) gain (dB) versus frequency in concurrent triple-band mode.

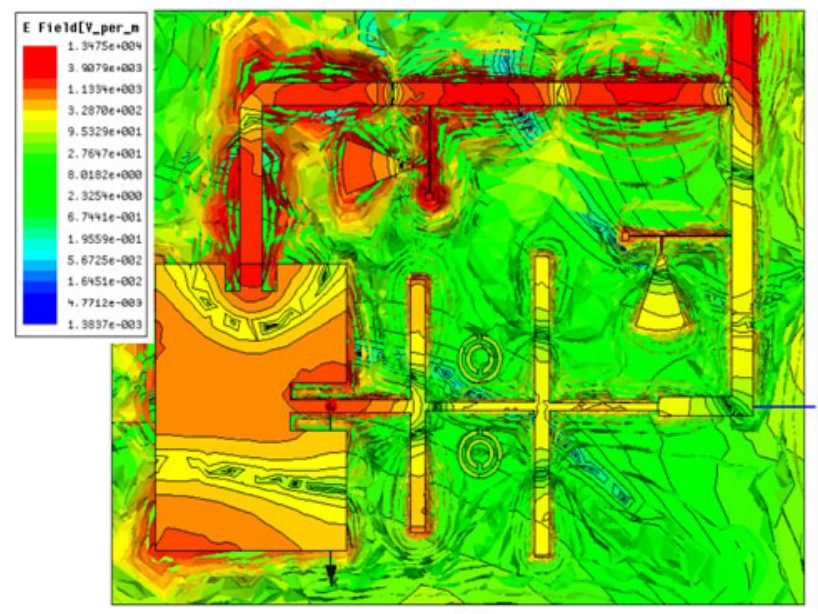

(a)

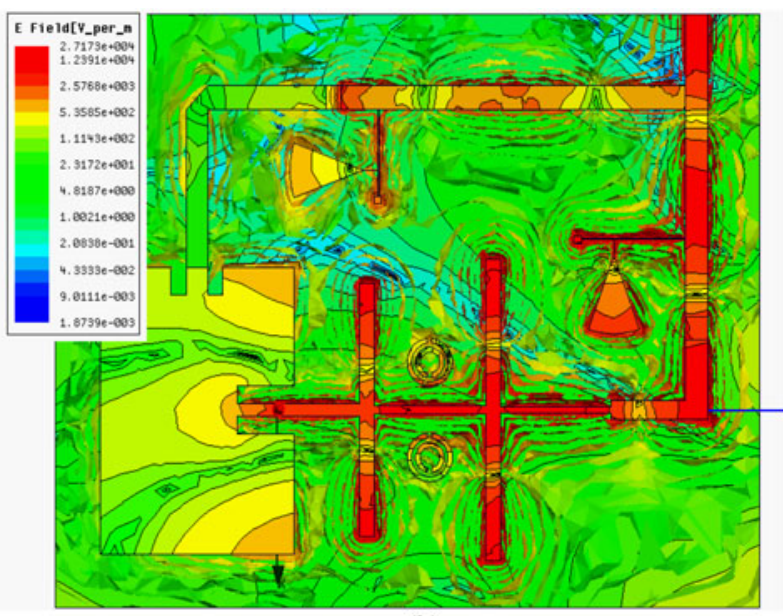

(b)

Fig. 12. Electric field distribution in (a) concurrent tri-band mode, (b) wideband mode.
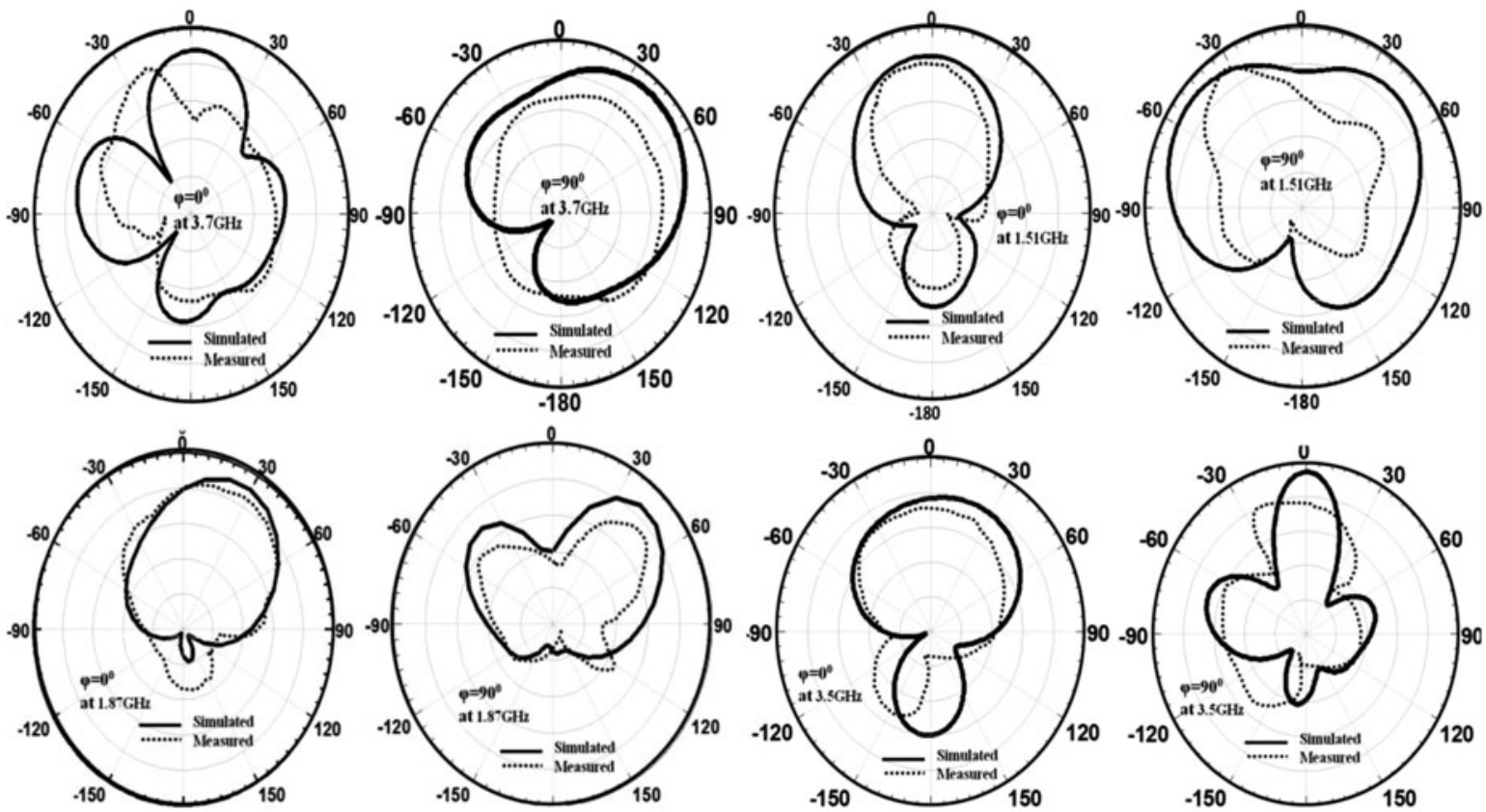

Fig. 13. Radiation pattern of the proposed antenna in $E$ plane $\left(\phi=0^{\circ}\right)$ and $H\left(\phi=90^{\circ}\right)$ 
under (red color) feed ${ }^{1}$ as compared with feed ${ }^{2}$, which shows the flow of maximum power through feed ${ }^{2}$ line.

The measured radiation patterns show stable responses and are in good agreements. Simulated and measured $E$ plane $\left(\phi=0^{\circ}\right)$ and $H$ plane $\left(\phi=90^{\circ}\right)$ pattern for $3.7 \mathrm{GHz}$ (wideband mode) and at $1.5,1.9,3.5 \mathrm{GHz}$ (tri-band mode) are stable and close to simulated one as shown in Fig. 13.

\section{CロNCLUSION}

A novel reconfigurable concurrent tri-band to wideband reconfigurable antenna using single radiating element for GSM, WLAN, Wi-Max application is presented. A broadband $\mathrm{J}-\mathrm{K}$ matching network is used to increase the impedance bandwidth, a pair of SRR to improve the return loss characteristics wideband mode and microstrip open stub to tune the frequency in tri-band mode. The simulated and measured values of antenna parameters are in agreement with each other.

\section{REFERENCES}

[1] Kim, T.H.; Park, D.C.: Compact dual-band antenna with double L-Slits for WLAN operations. IEEE Antennas Wireless Propag. Lett., 4 (2005), 249-252.

[2] Yang, F.; Zhang, X.; Ye, X.; Samii, Y.R.: Wide-band E-shaped patch antennas for wireless communications. IEEE Trans. Antennas Propag., 49 (2001), 1094-1100.

[3] Mak, A.C.K.; Rowell, C.R.; Murch, R.D.; Mak, C.L.: Reconfigurable multiband antenna designs for wireless communication devices. IEEE Trans. Antennas Propag., 55 (2007), 1919-1928.

[4] Abutarboush, H.F. et al.: A reconfigurable wideband and multiband antenna using dual-patch elements for compact wireless devices. IEEE Trans. Antennas Propag., 6o (2012), 36-49.

[5] Hamid, M.R.; Gardner, P.; Hall, P.S.; Ghanem, F.: Vivaldi antenna with integrated switchable band pass resonator. IEEE Trans. Antennas Propag., 59 (11) (2011), 4008-4015.

[6] Qin, P.-Y.; Wei, F.; Jay Guo, Y.: A wideband-to-narrowband tunable antenna using a reconfigurable filter. IEEE Trans. Antennas Propag., 63 (5) (2015), 2282-2285.

[7] Augustin, G.; Denidni, T.A.: An integrated ultra wideband/narrow band antenna in uniplanar configuration for cognitive radio systems. IEEE Trans. Antennas Propag., 60 (2012), 5479-5484.

[8] Pues, H.G.; Van de Capelle, A.R.: An impedance matching technique for increasing the bandwidth of microstrip antennas. IEEE Trans. Antennas Propag., 37 (1989), 1345-1354.

[9] Cao, W.; Zhang, B.; Liu, A.; Yu, T.; Guo, D.; Wei, Y.: Gain enhancement for broadband periodic endfire antenna by using split-ring resonator structures. IEEE Trans. Antennas Propag., 60 (2012), 35133516.
[10] Lee, J.-G.; Lee, J.-H.: Suppression of spurious radiations of patch antennas using split-ring resonators. Microwave Opt. Technol. Lett., 48 (2006), 283-287.

[11] Wang, W.; Gong, S.; Cui, Z.; Liu, J.; Ling, J.: Dual band-notched ultrawideband antenna with codirectional SRR. Microw, Opt. Technol. Lett., 51 (2009), 1032-1034.

[12] Baena, J.D. et al.: Equivalent-circuit models for split-ring resonators and complementary split-ring resonators coupled to planar transmission lines. IEEE Trans. Microw. Theory Technol., 53 (2005), 1451-1461.

[13] Rogla, L.J., Carbonell, J.; Boria, V.E.: Study of equivalent circuits for open-ring and split-ring resonators in coplanar waveguide technology. Spl. Issue Metamat. LHM IET Microw. Antennas Propag., 1 (2007), 170-176.

[14] Shirazi, M.; Li, T.; Gong, X.: Effects of PIN Diode Switches on The Performance of Reconfigurable Slot-Ring Antenna. IEEE Wireless and Microwave Technology Conf. (WAMICON), Florida, USA, 2015.

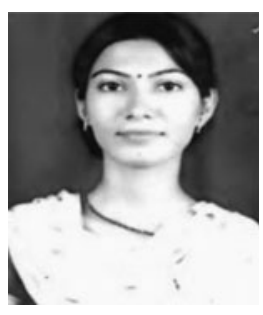

Sonia Sharma received the M.Sc. degree in Electronics Science from Maharshi Dayanand University, Rohtak and M.Tech in Electronics and Communication Engineering from UIET, Kurukshetra University, Kurukshetra. She is pursuing her Ph.D. in the area of Reconfigurable antenna from UIET, Kurukshetra University Kurukshetra.

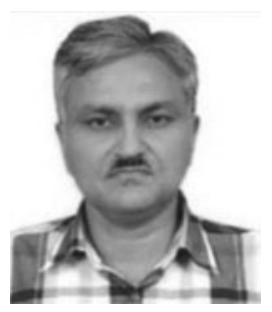

Dr. Chandra Charu Tripathi received the B.Sc. (Honors-Physics) and M.Sc. (Solid State Electronics Devices) degrees from Banaras Hindu University, Varanasi, followed by Master in Engineering (Microelectronics) in the year 1991 from BITS, Pilani, India. Since 1991 to 2003 , he worked at IDDC/HARTRON - a R\&D center of Haryana Government and was associated with design development and production of optoelectronics/opto-mechanical product for Indian defence industry. Presently, he is Professor in the Department of Electronics \& Communication Engineering at UIET, KUK. His research interests include optoelectronics products, including Photovoltaic devices, Optical devices, Printable electronics, microwave propagation, antenna, Rectenna, VLSI devices/technology Bio-MEMS/RF MEMS devices/sensors etc. $\mathrm{He}$ is senior fellow of IEEE besides being a member of various technical societies in the field of electronics engineering. He has more than 45 papers in refereed journals and 40 in National/ International conferences to his credit. 